\title{
O ESTADO DO CONHECIMENTO ACERCA DA TEMÁTICA DO GÊNERO NA EDUCAÇÃO BÁSICA
}

\section{Liliana Pincolini'; Eliane Aparecida Galvão dos Santos ${ }^{2}$}

\section{RESUMO}

Este estudo tem como objetivo apresentar o estado do conhecimento sobre pesquisas acerca da temática de gênero na educação entre os anos de 2016 e 2020. A partir disto foi mapeado as teses de doutorado e dissertações de mestrado do Catálogo da Coordenação de Aperfeiçoamento de Pessoal de Nível Superior (CAPES), tendo como recorte os trabalhos produzidos na área da educação. Desse material foi analisado duas teses de doutorado e onze dissertações de mestrado, totalizando treze documentos acadêmicos que estavam diretamente relacionados ao gênero na educação. Como resultado, verificou-se que o tema tem sido pouco explorado pela comunidade acadêmica na área das humanidades. Os trabalhos sinalizam para a necessidade de formação prévia e continuada para os profissionais que atuam com a educação, a fim de oportunizar um espaço de (re)construção de saberes e fazeres pedagógicos.

Palavras-Chave: Gênero; Desafio; Prática de Ensino.

Eixo Temático: Direitos, Políticas Públicas e Diversidade (DPD)

\section{INTRODUÇÃO:}

A temática de gênero tem tomado amplitude nos noticiários e nas redes sociais principalmente devido aos altos índices de violência sofridos tanto por mulheres como por LGBT's. Além disso, o tema é permeado por muitas concepções discriminatórias, advindas de uma cultura homofóbica, misógina e heteroformativa,

\footnotetext{
${ }_{1}^{1}$ Autor/Apresentador - UFN, MEHL, liliana.pincolini@ufn.edu.br

2 Doutora.Professora no Mestrado em Ensino de Humanidades e Linguagens da Universidade Franciscana.
} 
na qual os seres humanos se delineiam em apenas um binário homem/mulher, macho/fêmea, forte/fraco; não apresentando fora desses moldes outras configurações possíveis.

Levando em conta que o espaço escolar além de ser o de reprodução desses moldes, pode ser um ambiente de resistência, onde independente de aspectos ideológicos, culturais e religiosos passe a trazer o conhecimento científico como base de uma educação constitucionalmente laica.

O papel do (a) professor (a) como agente de questionamento do senso comum e na iluminação das ideias contra a discriminação seja de gênero, raça e credo é fundamental. Para Morin (2000) "[...] uma educação só pode ser viável se for uma educação integral do ser humano. Uma educação que se dirige à totalidade aberta do ser humano e não apenas a um de seus componentes." (MORIN, 2000, p. 11). Mas, para isto, nossos (as) educadores (as) precisam estar preparados (as) para saber tratar estas questões dentro do ambiente escolar.

Diante das inquietações referentes à forma como o tema tem sido percebido entre os (as) professores (as) de Educação Básica (EB) faremos um levantamento de produções sobre o assunto nos últimos cinco anos.

\section{MATERIAL E MÉTODOS}

Este estudo, caracterizado como um "Estado do Conhecimento", tem como finalidade mapear e analisar pesquisas sobre gênero entre os anos de 2015 e 2019. Dessa forma, esta investigação está alicerçada em uma pesquisa bibliográfica.

Nesse sentido, as pesquisas denominadas "estado da arte" ou "estado do conhecimento" trazem em comum:

[...] o desafio de mapear e de discutir uma certa produção acadêmica em diferentes campos do conhecimento, tentando responder que aspectos e dimensões vêm sendo destacados e privilegiados em diferentes épocas e lugares, de que formas e em que condições tem sido produzidas certas dissertações de mestrado, teses de doutorado, publicações em periódicos e comunicações em anais de congressos e de seminários (FERREIRA, 2002, p. 257). 
O percurso trilhado por este trabalho teve início na seleção dos documentos acadêmicos. Inicialmente, realizou-se uma busca no Catálogo de Teses e Dissertações da Coordenação de Aperfeiçoamento de Pessoal de Nível Superior (CAPES), datada em 04 de junho de 2021, pelo descritor "gênero e educação básica", o que identificou 1000 documentos acadêmicos publicados sobre a temática.

Na sequência, foi realizado o refinamento da pesquisa por meio da seleção do grau acadêmico, optando-se por mestrado e doutorado apenas. O lapso temporal foi delimitado por pesquisas publicadas entre os anos de 2016 e 2020.

Nesse sentido, percebe-se a necessidade de saber o que já foi produzido acerca da temática em referência e que nem sempre está disponível ao conhecimento da sociedade, conforme colacionado a seguir:

Sustentados e movidos pelo desafio de conhecer o já construído e produzido para depois buscar o que ainda não foi feito, dedicar cada vez mais atenção a um número considerável de pesquisas realizadas de difícil acesso, de dar conta de determinado saber que se avoluma cada vez mais rapidamente e de divulgá-lo para a sociedade (FERREIRA, 2002, p. 3).

Dessa forma, compreende-se que realizar um "Estado do Conhecimento" acerca das produções acadêmicas advindas de Programas de Pós-Graduação é de extrema relevância, haja vista que, muitas vezes, os resultados obtidos nas pesquisas nem sempre possuem um grande alcance. Por esse motivo, destaca-se a importância de se desenvolver uma investigação que trace um panorama sobre o conhecimento produzido sobre a temática.

\section{ANÁLISE DAS PRODUÇÕES CIENTÍFICAS ENCONTRADAS NO CATÁLOGO DE TESES E DISSERTAÇÕES DA CAPES}

Ao verificar, por meio do estado do conhecimento, as produções que abordam o tema gênero na Educação Básica no Banco de Dissertações e Teses da CAPES 
verificamos, que nos últimos cinco anos (2016-2020), a maioria das pesquisas são voltadas à área de educação.

Dentre um universo de 1.000 artigos, usando os descritores "gênero" e "educação básica", separamos de 25 pesquisas das quais analisamos 13. Desta maneira, apesar de possuir relevância social, o tema, ainda precisa ter maior número de pesquisas frente a real situação de exclusão e violência sofrida cotidianamente por mulheres e público LGBT's.

Diante desse cenário, apresenta-se uma análise abrangente das Teses e Dissertações publicadas no Catálogo da CAPES acessadas e classificadas de acordo com o ano de publicação.

\section{Tabela 1 - Produções científicas encontradas no catálogo de teses e dissertações da CAPES entre 2016 e 2020}

\begin{tabular}{|c|c|c|}
\hline \multicolumn{2}{|c|}{$\mathbf{N}^{\circ}$ de trabalhos encontrados } & $\begin{array}{c}\mathbf{N}^{\circ} \text { de trabalhos que se } \\
\text { aproximam da temática } \\
\text { pesquisada }\end{array}$ \\
\hline 2016 & 6 & 3 \\
\hline 2017 & 9 & 5 \\
\hline 2018 & 1 & 1 \\
\hline 2019 & 2 & 3 \\
\hline 2020 & 7 & 13 \\
\hline
\end{tabular}

Fonte: Tabela elaborada pelos autores com base na consulta ao Catálogo de Teses e Dissertações da CAPES, datada em 4 de maio de 2021. 
Diante desse cenário, apresenta-se uma análise abrangente das Teses e Dissertações publicadas no Catálogo da CAPES acessadas e classificadas de acordo com o ano de publicação.

Menezes (2016), na tese "Gênero, Ensino e pesquisa em Matemática: um estudo de caso", defendida na Universidade Federal da Bahia (UFBA). Menezes (2016) demonstra que se mantém em grande maioria das falas dos (das) docentes a visão cristalizada do conceito de gênero. Segundo Menezes (p. 194), parece prevalecer antigas representações sobre as habilidades cognitivas de homens e mulheres, assim como se cristaliza, através das gerações, a atribuição, apenas para as mulheres, do cuidado dos (as) filhos (as) e da família. Porém, o autor admite que em uma perspectiva otimista, pode-se dizer que está em curso, manifestada mudança gradual de comportamentos, apontando para uma equidade nas atribuições para homens e mulheres no que tange ao mundo privado. Menezes (2016, p. 195), destaca a importância de, a longo prazo, combater os preconceitos arraigados na sociedade e tornar mais rico e solidário o ambiente acadêmico, revelado em relações de gênero menos assimétricas e mais cooperativas.Demonstra desta forma, que ainda, mesmo que, num ambiente acadêmico, estas questões permanecem fechadas e discriminatórias, demonstrando a necessidade de uma mudança na ideia de que a área é masculina e não feminina.

Castro (2016), em sua dissertação "Gênero, diversidade sexual e educação: concepções de professoras da Educação Básica no Município de Paranaíba - MS", defendida na Universidade Estadual do Mato Grosso do Sul (UFMS).Ao explorar os trabalhos produzidos a partir dos discursos dos (as) educadores (as) pode perceber que em sua grande maioria, os (as) professores (as) trouxeram em suas falas discursos a respeito de gênero muito do que experienciam em suas vivências, seja na família, na Igreja, e nos discursos culturais sobre o assunto. Esta rede de discursos precisa ser questionada e até desconstruída pautada em conhecimentos científicos, já que o mesmo é bastante permeado pelo senso comum e por influências religiosas contrárias ao tema. Desta forma, a escola é um local de 
construção e desconstrução de preconceitos trazidos pelo senso comum e construídos historicamente pela nossa cultura extremamente patriarcal, branca e heterosexual. Castro (2016, p. 112), encerra a pesquisa com o questionamento: "será possível conceber uma escola livre do binarismo de gênero e da heterossexualidade compulsória?".

Mochi (2016), na dissertação "Afinal, do que é feita uma família? Famílias homoafetivas femininas: da (in)visibilidade às percepções hétero/naturalizadas de profissionais da educação básica”, defendida na Universidade Estadual de Maringá (UEM). Os resultados mostraram que é bastante presente na escola os discursos discriminatórios, necessitando políticas formativas mais consistentes nesta temática.

Silva (2017), na dissertação "Experiências e práticas pedagógicas em gênero e sexualidade: conflitos e potências em narrativas de professoras da educação básica”, defendida na Universidade do Rio de Janeiro (URJ). A autora pode constatar, apesar de vivenciar um momento histórico bastante influenciado pelo Movimento da Escola Sem Partido, que as ações desenvolvidas pelos (as) professores (as), embora tímidas, estão trazendo mudanças. Mas, identificou a falta de planejamento formal para o trabalho desta temática, relatando o aspecto marginal em termos de currículo.

Oliveira (2017), na dissertação "Normas de Gênero e heteronormatividade em uma Escola de Educação Básica em Acaraju (SE)", defendida na Universidade Federal do Sergipe (UFS). Com base na pesquisa foi possível observar que as noções sobre gênero e sexualidade são atravessadas pelos discursos biológico e religioso nas narrativas, definindo e fixando duas identidades de gênero possíveis e opostas. Assim, os discursos que atravessam as narrativas dos/das docentes atualizam uma norma hegemônica de masculinidade e feminilidade, reforçando a (re)produção da heterossexualização compulsória no currículo investigado, com poucas experiências de subversões. Também ficou explícita a necessidade de conhecimentos maiores sobre a legislação educacional e referente aos direitos humanos por parte dos docentes. A necessidade de uma formação continuada ficou 
evidenciada pois apesar da laicidade da educação pode-se perceber uma forte influência religiosa nos discursos dos educadores o que acaba por reforçar as discriminações sociais já existentes na sociedade em relação a famílias femeparentais. A visão de família é bastante marcada pela constituição mãe e pai do ideário religioso e não reflete a realidade plural e diversa das constituições atuais desta instituição. A pesquisadora alerta para a necessidade de transformação pelo qual a escola deverá percorrer para ser espaço democrático e de respeito à diversidade.

Vieira (2017), na dissertação "Identidade de gênero na escola: estigma e diversidade", defendida na Universidade de Taubaté. Os resultados demonstram a falta de conhecimento dos professores pela temática, inclusive de legislações presentes a nível estadual e também que alguns a confundem com questões de bullying e alunos com necessidades especiais. Alerta para a necessidade de formação continuada quanto às questões de gênero e das múltiplas identidades dele decorrentes. Chama a atenção para o papel da Escola em formar os futuros cidadãos, que hoje estão sentados nos bancos escolares, para que sejam pessoas mais tolerantes e respeitosas.

Brasil (2017), na dissertação "Gênero e sexualidade na Escola: da educação legal à educação real”, defendida na Universidade Federal do Espírito Santo. A pesquisa constatou que mecanismos excludentes encontram-se presentes no cotidiano institucional, algumas vezes de forma sutil, outras vezes de forma tão violenta e grosseira, que são capazes de alterar a trajetória escolar dos estudantes.

Silva (2017), na tese "Os movimentos das professoras educação básica do Espírito Santo em face às políticas públicas de gênero para a educação", defendida na Universidade Federal do Espírito Santo. O estudo demonstrou o avanço da temática nas práticas pedagógicas das professoras em relação ao tema, e que as mesmas foram potencializadas a partir das formações recebidas pela política pública GDE. 
Faria (2018), na dissertação "Concepções de gênero e sexualidade no ensino de Geografia em escolas públicas de Goiânia, Goiás”, defendida na Universidade Federal de Goiás.O estudo apontou a falta de formação inicial e continuada dos professores sobre os assuntos de gênero, sexualidade e heteronormatividade, faltando suporte teórico e prático para tratar tais abordagens no espaço escolar com ética e com equidade. Também destacou a importância da Geografia para com a busca da equidade e respeito às diferenças.

Wenning (2019), na dissertação "Docência de música e diversidade de gênero e sexualidade: um estudo com professores/as de música da educação básica", defendida na Universidade Federal do Rio Grande do Sul (UFRGS).Os resultados da pesquisa evidenciam as diferentes relações estabelecidas entre professores, música, sujeitos e gênero. Relata a importância de trabalhar com autoras e musicistas mulheres numa área ainda dominada por homens. Verificou-se que os docentes possuem diversas visões referentes a gênero e sexualidade que em sua maioria são fruto das suas vivências e não apreendidas a partir de suas formações.

Rossi (2020), na dissertação de mestrado "Gênero e educação em tempos de escola sem partido: compreensão de educadoras em debate", defendida na Universidade Federal do Paraná. Segundo Rossi (2020) mesmo após vinte anos da publicação dos PCN (BRASIL, 1998), verificamos que ainda existe muito trabalho a ser feito e um déficit na formação e capacitação de professoras/es para lidarem com as temáticas em torno da sexualidade, o que acarreta em pedagogias alicerçadas em concepções religiosas, higienistas e heteronormativas (ROSSI, 2020, p.110).

Desta forma, além de uma carência na formação de nossos professores, também passamos por uma retroação nas políticas que até então visavam uma cultura de direitos humanos e diversidade em vista de uma mudança política brasileira conservadora que subentende e reafirma os valores excludentes historicamente construídos no Brasil.

Sousa (2020), na dissertação de mestrado "Os (des)entendimentos de professores da educação básica sobre a temática gênero", defendida na 
Universidade de São Paulo (USP). As interpretações dos professores demonstram que ainda relacionam gênero ao sexo biológico e em grande parte são trazidas do seio familiar. Demonstra também que alguns, mesmo de forma tímida estão abertos a esta temática, para que a escola seja um espaço mais justo para todos.

Souza (2020), na dissertação "Relações étnico-raciais e de gênero no contexto das práticas pedagógicas: escrevivências e (re)invenções na Educação Básica", defendida na Universidade da Bahia (UBA). A partir da análise das narrativas e conforme as leituras e diálogo com autores vislumbramos que os maiores desafios são o diálogo entre as áreas do conhecimento e os componentes curriculares, as limitações do currículo tradicional e as possibilidades de interseccionalidade na construção de práticas pedagógicas antirracistas e antissexistas.

Desta forma, além de uma carência na formação de nossos professores, também passamos por uma retroação nas políticas que até então visavam uma cultura de direitos humanos e diversidade em vista de uma mudança política brasileira conservadora que subentende e reafirma os valores excludentes historicamente construídos no Brasil.

\section{CONSIDERAÇÕES FINAIS}

Com a análise das pesquisas foi possível verificar que a educação básica está grandemente marcada por discursos discriminatórios e binários de gênero e que a grande maioria dos educadores traz de suas vivências a maior parte de suas concepções apontando a necessidade de formação continuada sobre a temática para a preparação dos mesmos para o enfrentamento desta temática.

A partir da análise destes trabalhos foram possíveis diversas indagações: Diante desta retroação das pautas em torno das questões de gênero, como estas questões têm sido discutidas e trabalhadas no chão da escola pelos professores? Estes profissionais que constroem a educação brasileira na sala de aula, em contato 
com os estudantes percebem a importância desta temática na formação de cidadãos pacíficos, mais empáticos e justos para com os outros? Será que compreendem a importância de educar para a diferença? Será possível verificar a existência do mesmo na prática dos professores? Como definem gênero frente à complexidade deste conceito?

\section{REFERÊNCIAS}

BRASIL, A. P. Gênero e sexualidade na escola: da educação legal à educação real. 2017. Dissertação (Mestrado em Educação em Ciências e Matemática) Instituto Federal do Espírito Santo, Programa de Pós-graduação em Educação em Ciências e Matemática, Vitória, 2017. Disponível em: file:///home/chronos/u-a42c0bbdc2a59431693f1d686a535934db12000f/MyFiles/Dow nloads/MPECM_\%20Disserta\%C3\%A7\%C3\%A30\%20de\%20Mestrado-\%20modalid ade\%20profissional_\%20Turma\%202015-TE_\%20Ana\%20Paula\%20Brasil_\%20V\% 20FInal\%20em\%2003.04.2018.pdf. Acesso em: 21 maio 2021.

CASTRO, L. B. de. Gênero, diversidade sexual e educação: concepções de professoras da educação básica no município de Paranaíba - Dissertação (Mestrado em Educação) - Universidade Estadual de Mato Grosso do Sul, Unidade Universitária de Paranaíba, 2016. Disponível em: file:///home/chronos/u-a42c0bbdc2a59431693f1d686a535934db12000f/MyFiles/Dow nloads/Dissertacao\%20Leandro\%20Castro.pdf. Acesso em: 21 maio 2021.

FARIA, R. P. do N. Concepções de gênero e sexualidade no ensino de Geografia em escolas públicas de Goiânia, Goiás. Dissertação(Mestrado em Geografia) Universidade Federal de Goiás, Goiânia, 2018. Disponível em: file:///home/chronos/u-a42c0bbdc2a59431693f1d686a535934db120

00f/MyFiles/Downloads/Ruan\%20Pinheiro\%20do\%20Nascimento\%20Faria.pdf.

Acesso em: 21 maio 2021.

FERREIRA, Norma Sandra de Almeida. As pesquisas denominadas "estado da arte”. Educação \& Sociedade, São Paulo, ano 23, n. 79, p. 257-272, ago. 2002.

MENEZES, L. C. Gênero, ensino e pesquisa em matemática: um estudo de caso. 2016. Tese (Doutorado em Estudos Interdisciplinares) - Universidade Federal da Bahia, Faculdade de Filosofia e Ciências Humanas, Salvador, 2016. Disponível em:file:///home/chronos/u-a42c0bbdc2a59431693f1d686a535934db12000f/MyFiles/ Downloads/DINA\%20\%20_VERS\%C3\%830\%20FINAL\%20PARA\%20GR\%C3\%81F ICA.pdf. Acesso em: 21 maio 2021.

MOCHI, L. C. C. Afinal, do que é feita uma família? Famílias homoafetivas femininas: da (in)visibilidade às percepções hétero/naturalizadas de profissionais da educação básica. 2016. Dissertação (Mestrado em Ciências Sociais) - Universidade Estadual de Maringá, Maringá, 2016. Disponível em: file:///home/chronos/u-a42c0bbdc2a59431693f1d686a535934db12000f/MyFiles/Dow nloads/Luciene\%20Celina\%20Cristina\%20Mochi.pdf. Acesso em: 21 maio 2021. 
MORIN, E. Os sete saberes necessários à educação do futuro. 2. ed. São Paulo: Cortez, 2000.

OLIVEIRA, D. A. de. Normas de gênero e heteronormatividade em uma Escola de Educação Básica de Aracaju (SE). Dissertação (Mestrado em Educação) Universidade Federal de Sergipe, São Cristóvão, 2017. Disponível em: file:///home/chronos/u-a42c0bbdc2a59431693f1d686a535934db12000f/MyFiles/Dow nloads/DISSERTA\%C3\%87\%C3\%830\%20P\%C3\%93S\%20BANCA.pdf. Acesso em: 21 maio 2021.

ROSA, C. S. F. Relações de gênero no currículo de uma escola estadual com alto índice de desenvolvimento da educação básica. 2016. Dissertação (Mestrado em Educação) - Universidade Católica Dom Bosco, Campo Grande, 2016.

Disponível

em: file://home/chronos/u-a42c0bbdc2a59431693f1d686a535934db12000f/MyFiles/Dow nloads/CLEIR\%20SILV\%C3\%89RIO\%20FERREIRA\%20ROSA.pdf. Acesso em: 21 maio 2021.

ROSSI, J. P. G. Gênero e educação em tempos de escola sem partido: compreensões de educadoras em debate. 2020. Dissertação (Mestrado Interdisciplinar) - Universidade Estadual do Paraná, Programa de Pós-Graduação Interdisciplinar Sociedade e Desenvolvimento (PPGSeD), Campo Mourão, 2020. Disponível

em: file:///home/chronos/u-a42c0bbdc2a59431693f1d686a535934db12000f/MyFiles/Dow nloads/2020.Genero.e.educ.compreens\%C3\%B5es.de.educadoras.pdf. Acesso em: 21 maio 2021.

SILVA, D. V. da. Experiências e práticas pedagógicas em gênero e sexualidade: conflitos e potências em narrativas de professoras da educação básica. 2017. Dissertação(Mestrado em Educação) - Faculdade de Educação da Baixada Fluminense, Universidade do Estado do Rio de Janeiro, Rio de Janeiro, 2017. Disponível

em: file:///home/chronos/u-a42c0bbdc2a59431693f1d686a535934db12000f/MyFiles/Dow nloads/Dissertacao\%20Daniel\%20Vieira\%20Silva.pdf. Acesso em 21 maio 2021.

SILVA, E. M. da. Os movimentos das professoras da educação básica do Espírito Santo em face as políticas públicas de gênero para a educação. 2017. Tese (Doutorado em Educação) - Universidade Federal do Espírito Santo, Centro de Educação, Espírito Santo, $2017 . \quad$ Disponível em: file:///home/chronos/u-a42c0bbdc2a59431693f1d686a535934db12000f/MyFiles/Dow nloads/tese_11598_Tese\%20Erineusa\%20completa\%20entrega\%20PPGE.pdf. Acesso em: 21 maio 2021.

SOUZA, I. L. Os (des)entendimentos de professores da educação básica sobre a temática "gênero". 2020. Dissertação (Mestrado em Educação) - Universidade da Cidade de São Paulo, São Paulo, 2020. Disponível em: file:///home/chronos/u-a42c0bbdc2a59431693f1d6

86a535934db12000f/MyFiles/Downloads/Disserta\%C3\%A7\%C3\%A3o\%20de\%20me strado\%20em\%20Educa\%C3\%A7\%C3\%A3o\%20de\%20Igor\%20Leite\%20Sousa\%2 0(2020).pdf.pdf. Acesso em: 21 de maio 2021. 
SOUZA, V. O. de. Relações étnico-raciais e de gênero no contexto das práticas pedagógicas: escrevivências e (re)invenções na educação básica. 2020 . Dissertação (Mestrado em Educação e Diversidade). Universidade do Estado da Bahia, Bahia, 2020. Disponível em: file:///home/chronos/u-a42c0bbdc2a59431693f1d686a535934db12000f/MyFiles/Dow nloads/DISSERTA\%C3\%87\%C3\%830\%20MPED\%20-\%20VANEZA\%20OLIVEIRA \%20DE\%20SOUZA.pdf. Acesso em: 21 de maio 2021.

VIEIRA, P. H. Identidade de Gênero na Escola: estigma e diversidade. 2017. Relatório preparatório para qualificação, requisito parcial para obtenção do Título de Mestre pelo Programa de Pós-graduação em Educação - Mestrado Profissional em Educação da Universidade de Taubaté. Universidade de Taubaté, São Paulo, 2017. Disponível em: file:///home/chronos/u-a42c0bbdc2a59431693f1d686a535934db12000f/MyFiles/Dow nloads/Disserta\%C3\%A7\%C3\%A3o_Pedro\%20Henrique\%20Vieira_MPE.pdf.

Acesso em: 21 de maio 2021.

WENNING, G. G. Docência de música e diversidade de gênero e sexualidade: um estudo com professores/as de música da educação básica. 2019. Dissertação (Mestrado em Música) -- Universidade Federal do Rio Grande do Sul, Instituto de Artes, Programa de Pós-Graduação em Música, Porto Alegre, 2019. Disponível em: file:///home/chronos/u-a42c0bbdc2a59431693f1d686a535934db12000f/MyFiles/Dow nloads/Gabriela\%20Garbini\%20Wenning.pdf. Acesso em: 21 de maio 2021. 